\title{
A irrepetibilidade da arte
}

\author{
Morgana Recha* \\ Estevan de Negreiros Ketzerb \\ a Universidade Federal do Rio de Janeiro, Centro de Filosofia e Ciências Humanas. Rio de Janeiro, RJ, Brasil \\ ${ }^{b}$ Pontifícia Universidade Católica do Rio Grande do Sul. Porto Alegre, RS, Brasil
}

\begin{abstract}
Resumo: 0 artigo trata dos elementos ligados à repetição como característica da intencionalidade estética nas obras de arte. Mostramos como a repetição, acompanhada da reflexão freudiana acerca do estranho (Unheimlich), é evidenciada na necessidade do artista de repetir um novo encontro com a obra, na intenção de produzir um novo encontro com o mais radical de si. Ilustramos esta ideia com os aportes trazidos pela teoria estética contemporânea de Jacques Derrida e Georges Didi-Huberman, que observam o fenômeno da desvalia (désaisissement), certa restrição de visibilidade que causa uma cegueira do objeto. Apresentamos uma breve resenha clínica sobre um caso atendido por nós em que a vivência de emoções é obstaculizada, favorecendo o aparecimento de uma fala repetida na dimensão da clínica.
\end{abstract}

Palavras-chave: repetição, estranho, estética, desvalia.

\section{O medo é a extrema ignorância em momento muito agudo. \\ $O$ medo $O$. O medo me miava. João Guimarães Rosa}

\section{Introdução}

Antes da passagem à segunda tópica, em 1920, Freud não havia vinculado arte e violência psíquica. Em quase todas as menções que faz à experiência artística, antes disso, a ideia predominante é de que a relação do psiquismo com o objeto artístico é a de realização de um desejo inconsciente. Esta questão se mostra em, pelo menos, dois registros distintos: o do estudo da criatividade do artista e o do estudo do efeito causado pelas obras de arte em quem as observa ou interage com elas.

Sendo uma constante no legado freudiano, a investigação sobre a experiência artística sofre diversas modificações. Na primeira tópica, aparece subordinada às leis do princípio do prazer: o prazer de fruição. Com a introdução do narcisismo, Freud vai, pouco a pouco, assumindo que a relação humana com o objeto artístico pode ir além da mera contemplação, associando sua face de angústia e excesso à incidência diante do estranho ${ }^{1}$.

\footnotetext{
Endereço para correspondência: mo.rech@gmail.com

1 O termo Unheimlich contém diversas nuances em sua tradução. Por esta razão também estamos pautados pelas recentes traduções de Paulo César de Souza (Freud, 1919/2010), com o termo inquietante, e de Ernani Chaves e Pedro Heliodoro Tavares (Freud, 1919/2019), com a ideia de infamiliar. Também consideramos o uso de Luiz Alberto Hanns (1996) acerca da pluralidade do termo que, além de estranho, também transmite as ideias de lúgubre, sinistro, e macabro. Ressaltamos a importância do comentário de Hanns (1996) acerca desse problema tradutório da língua alemã para a nossa língua: "Nesse artigo, Freud aponta para o fato de que
}

Associar a experiência artística à inquietante estranheza corresponde a considerá-la como uma manifestação particular da compulsão à repetição, veiculada pela pulsão de morte. Entretanto, se há algo que caracteriza o objeto artístico, é a sua irrepetibilidade. $\mathrm{O}$ que o artista busca é nunca se repetir, embora afirmem alguns poetas, por exemplo, que a literatura é uma sucessão de cópias.

Para refletir sobre este problema, abordaremos "O estranho" (Das Unheimlich), seguido de um retorno a três momentos em Freud que mostram possíveis raízes da ideia da arte enquanto terreno da inquietante estranheza. Tomaremos como referência as proposições do poeta contemporâneo Alberto Pimenta, que ajudam a compreender que a arte entendida nestes moldes é uma arte de intenção estética, que guarda o paradoxo: repetir compulsivamente para não se repetir nunca.

\section{Duas observações}

I. Se levarmos em consideração a teoria de que criação e apreensão de arte são partes do mesmo processo, somos inclinados a pensar que Freud, em suas investigações, procurava por uma explicação para a arte de intenção estética, isto é, capaz de provocar movimentação pulsional. A arte dita de "raiz

a palavra alemã teria certa ambiguidade, oscilando entre o 'familiar' e o 'desconhecido'. Relaciona tal ambiguidade com a sensação de inquietude do sujeito pelo retorno do material recalcado (portanto conhecido), o qual volta sob a forma de algo desconhecido e assustador" (p. 231). O autor nos apresenta que o conceito de estranho pode ser utilizado no texto de Freud como parte pessoal da participação na ideia de secreto e oculto. Por esta razão continuamos na via tradutória de Jayme Salomão (Freud, 1919/2006). 
estética", para a crítica literária, é um conceito que fica visível e teorizado principalmente na modernidade, quando artistas dão voz à dimensão violenta das expressões artísticas ${ }^{2}$.

II. Freud, por seu turno, mais interessado em investigar o psiquismo do que a especificidade da arte, analisou especialmente esculturas renascentistas e obras literárias modernas, com relevo para a literatura fantástica, dada a sua essencial familiaridade com os mistérios dos processos inconscientes que o cercavam. Além disso, articulou a questão da arte a outros temas, como, principalmente, a manifestação do chiste e do sonho. Todos estes objetos de estudo do autor remetem ao que seria o "campo da estética", no qual a inquietante estranheza exerce papel fundamental, correspondendo a uma região de indiferenciação entre o eu e o outro, com tendência a se repetir. No segundo dualismo pulsional, Freud admite que a experiência artística se realiza particularmente nessa região.

\section{"O estranho" e a arte}

Pouco tempo antes de formalizar a pulsão de morte, em 1919, Freud publicava "O estranho", texto no qual faz uma análise do conto $O$ homem de areia (Der Sandmann), escrito por Ernst Theodor Amadeus Hoffmann, em 1915. O conto é classificado dentro do gênero fantástico, o que permite a Freud realizar uma análise tipicamente psicanalítica.

Porém, mais importante do que apresentar suas habilidades de crítico literário, Freud parece interessado em entender a natureza do efeito de estranhamento que esse tipo de texto provoca. Será pelo caráter misterioso e dúbio, típico desse tipo de narrativa? Esta primeira hipótese é logo descartada, ao passo que o autor a considera demasiado simplista. Será pelo fato de que o texto convoca o complexo de castração - ou seja, o retorno do recalcado? Esta, mais fundamentada e desenvolvida, é a hipótese que leva Freud até a teoria a respeito do duplo e da compulsão à repetição. A leitura evoca a presença do recalcado que, por sua vez, é sentida como estranha por

2 A título de circunscrição do tema, alguns teóricos defendem que tal dimensão tem início com o romantismo alemão e culmina com o "Manifesto surrealista" de André Breton, especialmente o Segundo, em que Breton (2001) escreve: "O ato surrealista mais simples consiste em sair à rua com dois revólveres e atirar ao acaso sobre a multidão" (p. 155). Não podemos deixar de lado também a contribuição da assim chamada escola do formalismo russo, com o grupo Opojaz (Sociedade para o Estudo da Linguagem Poética), ao reconhecerem, no início do século XX (1910-1930), que a arte é o pensamento por imagens e a fundamental contribuição de Viktor Chklóvski (2011): "o caráter estético do objeto, o direito de relacioná-lo com a poesia, é resultado de nossa maneira de perceber; chamaremos de objeto estético, no sentido próprio da palavra, os objetos criados mediante procedimentos particulares, cujo objetivo é garantir para tais objetos uma percepção estética" (p. 86). ser e não ser, ao mesmo tempo, familiar. Isto pressupõe que há uma cisão no ego, sendo que uma das partes de seu duplo possui tendência a se repetir compulsivamente: "há uma duplicação, divisão e intercâmbio do eu. $\mathrm{E}$, finalmente, há o retorno constante da mesma coisaa repetição dos mesmos aspectos, ou características, ou vicissitudes, dos mesmos crimes, ou até dos mesmos nomes" (Freud, 1919/2006, p. 252).

A partir daí, outro problema aparece aos olhos de Freud. Então, se as obras de arte têm a capacidade de produzir a sensação do estranho, será porque elas carregam em si o cerne da repetição? As obras de arte são criadas com esse objetivo ou a compulsão à repetição é a própria matéria-prima da criação artística? "Existem muito mais meios de criar efeitos estranhos na ficção, do que na vida real" (Freud, 1919/2006, p. 266). O autor afirma situando assim a ficção como uma possibilidade ímpar de expressão da inquietante estranheza ou, dito de outro modo, um de seus terrenos privilegiados.

A literatura, neste contexto, aparece como um espaço intermediário entre o que hoje podemos considerar investigação psicanalítica e investigação estética, ambas desenvolvidas por Freud, o que traz complexidade ao cerne do método psicanalítico. Isso auxilia Freud a diferenciar outras questões referentes ao limite entre ficção e realidade, de modo a entender que a arte opera uma espécie de prolongamento do espaço da inquietante estranheza, também limítrofe em sua essência.

Antes de avançar com nossas considerações, vejamos três momentos anteriores que indicam os pilares da construção freudiana acerca do fenômeno estético e sua estranha repetição.

\section{Três momentos anteriores}

Antes mesmo da introdução do narcisismo, Freud já levantava pontos importantes em torno da questão da experiência artística, que parecem estar na base do próprio entendimento da inquietante estranheza. Esses pontos ficam evidentes, pelo menos, em três textos: "Os chistes e sua relação com o inconsciente", de 1905; "Delírios e sonhos na Gradiva de Jensen", de 1907; e "O Moisés de Michelangelo", de 1914, mesmo ano de "Sobre o narcisismo: uma introdução".

Com relação aos chistes, o que Freud propõe é a ideia de prazer estético intimamente relacionado à particularidade da forma, sugerindo que um chiste tem o caráter de rompimento na cadeia do princípio do prazer, justamente pelas características formais específicas. Não sendo considerado pelo autor como uma "necessidade vital" ou "séria", um chiste produz a espécie de prazer descompromissado, com um fim em si mesmo. Trata-se, sim, de um auxiliar ao prazer; um prazer estético, de fruição, é um prazer lúdico, independentemente de uma dimensão mais primitiva. A natureza desse prazer estético, no chiste, é da ordem dos mesmos mecanismos 
presentes no sonho: o deslocamento e a condensação, os quais Freud também associará à criação artística.

Pouco tempo depois, o autor publica uma análise do conto "Gradiva", do escritor Wilhelm Jensen, que narra uma experiência de deslocamento e condensação, elementos do processo primário (Laplanche \& Pontalis, 1967/1970), entre uma imagem que afeta psiquicamente o personagem - a obra de arte - e a imagem idealizada de uma figura de sua infância. Trata-se de uma trama complexa promovida por Freud, que inclui uma série de elementos que formariam o efeito estético: o escritor, o personagem, a produção onírica e a obra de arte, apoiados sob a mesma base de mármore, isto é, sob a mesma forma: a primitiva "Gradiva", escultura que data da metade do século II a.C. e que, aparentemente, deixa o próprio Freud impressionado. Com efeito, podemos dizer que um dos objetivos do texto é investigar o enigma da atividade de escrita literária, incluindo a dele próprio, Freud escritor, como podemos ver no trecho seguinte:

Nessa disputa sobre a avaliação dos sonhos, os escritores parecem estar do lado dos antigos, do público supersticioso e do autor da Interpretação dos Sonhos. Quando fazem sonhar as personagens que sua fantasia criou, obedecem à experiência cotidiana de que os pensamentos e afetos dos indivíduos prosseguem durante o sono, e buscam retratar os estados de alma de seus heróis mediante os sonhos que eles têm. (Freud, 1907b/2006, pp. 14-15)

Como fica claro, a experiência estética da escrita e da leitura, nesse momento do pensamento freudiano, atenderiam ao processo de elaboração onírica regido pelo princípio do prazer. Nessa elaboração, o que está em causa é o clássico conflito do primeiro dualismo pulsional, qual seja o entrave entre pulsões sexuais e pulsões do ego, que trazem como efeito o delírio de natureza onírica: "O que nele se desenvolveu foi uma luta entre o poder do erotismo e o poder das forças que o reprimiam, luta esta que se manifesta como delírio" (Freud, 1907b/2006, p. 51)

O efeito estético do leitor também é destacado na reflexão, questionando a posição ativa da leitura, o que nos leva até uma estética da recepção ou à ideia de que a literatura existe apenas quando se estabelece a comunicação efetiva entre autor e leitor. Como se sabe, Freud não se furta em manifestar suas experiências como leitor e expectador das obras de arte que analisa: "Nesse ponto, a tensão em que até agora nos mantém o autor transforma-se por um momento numa dolorosa perplexidade. Evidentemente não foi só o nosso herói quem perdeu o equilíbrio. Também ficamos desorientados com o aparecimento de Gradiva" (Freud, 1907b/2015, p. 26).

O texto da Gradiva precede a publicação de "Escritores criativos e devaneios", também de 1907, no qual Freud (1907a/2006) procura esclarecer alguns pontos da discussão apresentada, promovendo uma articulação com o brincar infantil. O autor afirma que a natureza da atividade artística tem bases na atividade lúdica da infância, cujo fim é substitutivo, qual seja o de expressar uma sensação imaginativa desprazerosa em forma de realidade objetiva prazerosa. De modo geral, é uma hipótese que situa a experiência com a literatura no registro do devaneio. A experiência artística, tanto a de criação como a da leitura imaginativa, causa prazer enquanto pseudo-devaneio. O pseudo-devaneio causa um prazer que Freud chama de fruição.

Se até este momento do legado freudiano, a arte em sua dimensão estética ainda não se encontrava inserida na ordem das necessidades (Loureiro, 2003), a partir de 1914, precedendo a introdução do narcisismo, a relação entre arte e necessidade começa a aparecer. Em "Moisés de Michelangelo", nesse mesmo ano, Freud introduz elementos mais complexos à atividade artística, principalmente em função da admissão da onipotência humana. Ao verificar que a obra de Michelangelo permite uma multiplicidade de leituras, Freud conclui que não é só à realização de desejos inconscientes que a arte se submete; o artista empreende uma realização narcísica na obra, provocadora da pulsão de domínio, como assinala Schneider (2008). Sentindo-se num estado de "paralisia" pela escultura de Michelangelo, Freud sente como se "pertencesse à turba sobre a qual seus olhos [os de Moisés] estão voltados - a turba que não pode prender-se a nenhuma convicção, que não tem fé nem paciência e que se rejubila ao reconquistar seus ilusórios ídolos" (Freud, 1914/2006, p. 255). Dessa forma, passa a admitir que a experiência artística abrange uma dimensão de arcaísmo, ou melhor dizendo, Freud percebe que na arte há a urgência de sensações primitivas para além da elaboração de conteúdos recalcados.

\section{Inquietante estranheza e repetição}

Nos três momentos que sublinhamos, nota-se que a evolução do pensamento de Freud tende a considerar a arte como um objeto pelo qual não se passa indiferentemente. Nessa construção que apresentamos, a experiência artística se situa em um registro bastante primordial do desenvolvimento psíquico, cuja tendência a se repetir é permanente.

No pensamento freudiano, os sonhos, atos falhos e a fruição estética são manifestações que encontram um fio condutor até o primitivismo da vida psíquica, alcançando eco numa dimensão inconsciente tomada pelas sensações e pelas imagens. As expressões artísticas fariam, então, um retorno até um estágio em que um aparente "vacilo" das fronteiras psíquicas pode ser convocado, já que é próprio dos objetos artísticos promover uma reconfiguração das ligações entre palavras e imagens.

Fora das experiências artísticas, no entanto, a sensação de "vacilar de si" é trabalhada por Freud como manifestação da cisão do ego, que se torna estranho a si. A inquietante estranheza seria, então, a zona onde se 
passam os acontecimentos dessa natureza, regidos pela ação da pulsão de morte, que invadiria um ego que falha em delimitar sua opacidade; falha em alcançar a sensação de "estar em si". Sua atuação é repetitiva no psiquismo, por engendrar uma energia libidinal de cunho anárquico, oposta à pulsão de vida que visa à ligação.

Essa articulação entre arte e pulsão de morte é um ponto complexo, do qual uma série de autores discorda. Michel de M'Uzan (2010, 2012, 2015), por exemplo, um autor que rejeita a existência da pulsão de morte, admite a leitura freudiana sobre "O estranho" em seu acontecimento estético, porém define esse evento como um fenômeno que caracteriza o estado naturalmente móvel das fronteiras psíquicas. A tendência a se repetir não ocorre, segundo $\mathrm{M}^{\prime}$ Uzan, pela ação da pulsão de morte, mas pela permanência do encontro com a alteridade e, diante dela, do impulso pela afirmação identitária. A estranheza, nessa leitura, é uma zona intermediária que favorece a relação permanente entre os registros eu-outro e eu-corpo, como uma espécie de "negociação" (Gagnebin, 2015, p. 151) dessa fronteira. A atividade artística, de acordo com M'Uzan, se daria justamente neste território. O artista é, para este autor, um negociador constante, o que o torna um adicto à abertura permanente da região da estranheza. De certa maneira, é uma ideia implícita em Freud, evidente, por exemplo, em 1917, na conferência XXIII, em que o autor afirma que o artista não deixa de testar a realidade e que a arte, diferentemente do sintoma, não se repete da mesma maneira.

A ideia de "sentimento oceânico" designa a inquietante estranheza, indicando o fenômeno fusional característico da atividade artística. O retorno ao estado de consciência "de tipo oceânico", de acordo com Lehalle (2012, p. 166), é comum às experiências de criação artística como consequência da relação de unificação que ocorre entre obra, em sentido material, e artista.

A obra de arte, nesse sentido, opera como um instrumento de negociação na zona limítrofe entre vida e morte, eu e outro, interno e externo, material e psíquico. De acordo com M'Uzan (2010; 2012; 2015), a produção de uma obra literária, por exemplo, tem como fim último uma forma de documentação do seu autor, que se serve de estados de "despersonalização" para que a obra exista. Nas palavras de Terrapon (2012),

a atividade artística ... é um modo de se afirmar vivo ao tentar entrar em contato com o motor da vida. É também um modo de descobrir sua própria relatividade diante da imensidão ... pelo hábito de sonhar acordado, pelo trabalho artesanal da matéria gravada, eu sinto a verdade da alternância da vida à morte, e da morte à vida. (p. 167)

A transgressão linguística, social e política que a arte empreende, responde, nessa perspectiva, a uma busca identitária compulsivamente reaberta e, nesse contexto, todo o projeto freudiano de associar arte e narcisismo é base fundamental. Responde pela via de uma intensidade inominável, experiência tão clara e lúcida para aquele que a recebe, porém imensamente complexa de ser traduzida ou mesmo transmitida para o outro. Isso ocorre com toda a experiência que se mostra maior do que nossa apreensão cognitiva, o excelso que está tão ligado à linguagem da psicanálise, o que ele é? Pergunta impossível, como já falamos, mas talvez nas fissuras de seu acontecimento inominável possamos ter uma ideia de sua entrega, pois ali nos foi permitido ter acesso a algo do profundo canal de sua abertura. Esse aspecto é parte do famoso dilema do perto e distante que parece conduzir a experiência de quem caminha em busca de si e o que encontra são pesados temores pelas descobertas durante a análise: por um lado, perto, pois nos acompanha; por outro lado, distante, pois teremos de fazer um esforço de repetição contínua quando a coisa se mostra praticamente inacessível pela consciência. Eis que recebemos os efeitos de um toque inconsciente, assim como a asa da loucura que pousou sobre a cabeça de Stéphane Mallarmé após a leitura da Fenomenologia do espirito, de Hegel. Essa descoberta do outro em nós mesmos, descoberta vívida de partículas autorais e sensíveis a serem desbravadas, enfrentadas, captadas por máquinas que pensam, exteriores a nós, e a serem desenvolvidas por nossa internalidade.

\section{O objeto do olhar e sua aparente repetição}

De uma maneira ou de outra, o que parece assente é que a arte é, de fato, um objeto que entraria nessa cadeia repetitiva de negociação entre fronteiras: "o tal centro poético do indizível, a tal presença não muito evidente desse desiquilíbrio entre a inquietante suspensão de forças de vida e de morte" (Pimenta, 2003, p. 99). Nessa leitura, tal negociação pretende fazer que o eu permaneça, repetindo-se.

Contudo, paradoxalmente, em seu plano material, o objeto artístico em si é justamente irrepetível. No campo da arte, a irrepetibilidade é o que afirma a intenção estética da obra: causar mais impressões, mas impressões que, dentro da pessoa que a sente, sejam reais, autênticas. A busca da autenticidade no trabalho daquilo que avança para além das tentativas conceituais e de colocar a palavra como elegância ou erudição. A palavra passa em um instante se seu fator não se fizer tocar na correspondente sensibilidade daquele que experimenta a obra. Isso significa romper com uma ideologia da arte como entretenimento, pois a arte exige uma libertação do nível abstrato para o concreto. Ela se concretiza quando suas relações se dispõem a serem percebidas, ainda que não compreendidas; quando a necessidade do outro se faz ouvida em algum nível. Ali o pensar se torna um pesar, quando aquilo que pensa se mostra irrealidade e espessura que corroem dentro uma ausência plena, um desencontro. 
Nesse ponto, pensamos no termo francês désaisissement (abandono ou desinvestimento), que pode ser pensado tal como a perda do objeto e, portanto, à necessária alienação que vemos crescer em volta do estatuto da arte na vida das pessoas em nossos tempos atuais. Désaisissement, tal como a tentativa de Antonin Artaud (Derrida, 1967) ao chamar o nome de Deus em vão. Essa é metáfora do abandono da linguagem na era em que se acreditou alcançar o absoluto por meio de sua crença em conceitos anteriores aos acontecimentos mais ruidosos de nossos tempos. E, estranhamente, quando Deus se manifesta, é na forma de Satanás - termos utilizados por Artaud - que o asco e a sujeira sujeitam à realidade, uma mesma realidade que não reconhece sua aparição como efeito estético.

Nessa sombra mais escura de todas, ranhura da cavidade rachada, ali também se repete como para expurgar os temores das sombras. Não menores são as dificuldades de uma resistência que se aproxima fortemente quando o corpo se assusta com o que encontra de seu impossível. Ele se desvincula, entre lágrimas, paralisias ou raiva. $\mathrm{O}$ corpo adormece no aconchego do efeito que lhe acompanha tamanha a gravidade do encontro. Um encontro que toca quando menos se espera e sem convite, "me tocou antes que desejasse ver" (Derrida, 2011, p. 19, tradução nossa). Tocar na esperança de se sentir tocado também é parte do que vemos no panorama da arte, pois é quando justamente a arte começa a nos tocar por via de nossa incapacidade de nos sentirmos tocados por ela tal como os nossos sentidos estão acostumados. Essa experiência de certa cegueira atinge também o filósofo argelino Jacques Derrida (2010) quando, diante da morte de sua mãe, ele reflete:

A aperspectiva obriga-nos então a considerar a definição objetiva, a anátomo-fisiologia ou a oftalmologia do punctum caecum, por sua vez como uma simples imagem, um índex analógico da própria visão, da visão em geral, daquela que, vendo-se ver, não se reflete, no entanto, não se "pensa" no modo especular ou especulativo e que, por isso mesmo, assim se cega, neste ponto do "narcisismo", nisso mesmo que ela se vê olhar. (Derrida, 2010, p. 59)

Isso diz respeito a, justamente, todo o traçado da superfície que cega aquele que a produz. E não será essa também parte da irremediável loucura que a obra de arte é capaz de deslocar nossa visão? E como captar a parte da matéria que se eximiu de se pensar? O retraimento das coisas que nos faz suspeitar de que a sensibilidade engana a razão, mas o espectro sensível que se adianta a nós, na promessa do encontro. Talvez nesse ponto nossa insistência em dar um nome para o que vemos se apresse a ponto de subverter o que é visto. O que enxergamos nos atravessa justamente na parte que não conseguimos denominar. O que vemos projeta nossa ilusão sobre um ideal de ver: "ver só se pensa e só se experimenta em última instância numa experiência do tocar" (Didi-Huberman, 2010, p. 31). E por isso há uma aprendizagem por meio do ver o ver do outro, em resposta ao nosso desejo de ver como a totalidade da experiência que se acreditava imparcial ou mesmo neutra, a partir do lugar em que se é observado.

Se, por um lado, esse efeito estético traduz bem aquilo que remove o olhar de sua aparente atmosfera de proprietária do ver, temos de levar em conta que essa insistência, repetição persecutória, oprime também o que é visto. É quando o visto se revela nas mãos do artista a invenção criativa que temos o momento mais importante de descentramento da obra de arte do discurso. Discursos que por vezes são etéreos e estéreis, falando apenas do preconceito, e não do encontro que envolve o evento (évènement).

\section{Um caso de desvalia}

Para nós tem sido importante dar o contorno estético acerca de considerações em nossa clínica. Estamos tratando da questão da desvalia (désaisissement) e do que inquieta diante de um sutil abandono do olhar, fato este que gera uma repetição em seu mostrar-se ao mundo. Não por nada, em nosso mais recente trabalho (Rech \& Ketzer, 2017), levantamos o problema do saisissement (apreensão ou captura) do estético diante do retorno de um ego corporal, num ir e voltar de si mesmo (M'Uzan, 2010). Já neste artigo queremos fazer o caminho inverso e mostrar o que sofre o abandono desse olhar, porém sem poder anular seu vestígio. Para tanto temos a intenção de realizar uma vinheta clínica ${ }^{3}$. Não é nosso interesse simplesmente assinalar sua passagem em fenômenos clínicos, mas também mostrar o horizonte de sua sensibilidade e de sua arte, neste ponto que toca tanto a psicanálise como a ciência da transformação dos afetos a partir de um desenvolvimento das percepções. Freud foi um dos responsáveis por nos mostrar como o ego é capaz de alucinar diante da frustração à ausência de satisfação (Freud, 1911/2006), pois percebe o quanto uma descarga motora participa do processo de pensar, ligando-se a atividades aparentemente deslocadas da percepção, mas transpondo a consciência pela ação da atenção e da memória residual das experiências travadas. A figura do artista possui uma originalidade peculiar ao renunciar a realidade e, assim, investir na fantasia.

\footnotetext{
3 O paciente foi atendido por Estevan de Negreiros Ketzer. Para conferir mais fidedignidade às características de uma sessão de análise, optamos por usar nos trechos a seguir a primeira pessoa do singular ao nos referirmos aos diálogos durante os atendimentos de Jaco. O nome Jaco não foi escolhido por acaso. Inspiramo-nos na figura de Jaco Pastorius por ser o nome de um famoso contrabaixista norte-americano, reinventor do instrumento, considerado por muitos o fundador do punk-jazz devido ao seu estilo de vida marginal e mendicante.
} 
É a um artista que a vinheta clínica se refere. Jaco vem de muito longe, lá de onde as violas tocam. O olhar e o cenho sempre enrugados demonstram certo cansaço com a vida. Na verdade, sua história não lhe rendeu grandes frutos, por isso o melhor que conseguiu fazer foi estudar. Também caiu de skate muitas vezes até esse momento, algo que fazia como gesto de revolta durante sua adolescência e que agora fazia com sua bicicleta. Por ser músico popular, parecia que a madeira de seu instrumento sempre empenava e, com isso, ele brincava: "metade da vida afinando, e a outra metade da vida reclamando que está desafinado". A anedota era boa, realmente representa muito bem a condição das coisas sem mobilidade na vida de Jaco. Tudo parecia enormemente desconfortável e, ao mesmo tempo, controlável por certas concessões que vinha fazendo. O mais interessante é que algumas delas não envolviam apenas recursos financeiros esparsos, mas sim as pessoas à sua volta. Jaco precisava delas e, quando elas não se aproximavam, ele se sentia solitário. "Fui ao show do Egberto Gismonti na Sala São Paulo. Eu estava sozinho". "E como foi ter ido lá?", perguntei para ele. "Foi incrivel!", respondeu. "O que te chamou mais atenção lá no show?" Jaco se cala, confessa não se lembrar do show.

Não faz tanto tempo, mas esse fato se relaciona muito com uma dificuldade que já se apresentava em nossos encontros acerca do que Jaco parecia sempre tão animado ao se aproximar, mas sem poder estar inteiro para aproveitar o que tanto o excitava. "Repare que você não recorda o que aconteceu durante a apresentação. $\dot{E}$ como se você simplesmente não percebesse o que aconteceu contigo", disse para ele. "Quando venho aqui, pareço tremer o tempo todo..." Ele disse isso já em nossos primeiros meses de trabalho. Eram comuns os momentos em que não conseguia deixar a música fluir e, por vezes, sentia-se sozinho, achando que seus colegas eram muito superiores em conhecimentos sobre música do que ele.

Mais do que isso, era sua fala muito racional que por vezes não aceitava minha participação. Era como se fosse atrapalhar, pois "tremer" era aquilo que ele gostaria que continuasse do mesmo jeito. Perceber sua música também passava por minha percepção, mas o discurso sobre sua música parecia convencê-lo e inclusive protegê-lo da desafinação que o acompanhava o tempo todo. $\mathrm{E}$ as dimensões, ao invés de aumentarem sua capacidade de elaboração, o aprisionam dentro de si, o desqualificam, como coisas, tornam-se previsíveis e pouco prazerosas. Logo ficou mais nítida a culpa pelas coisas que carregava consigo.

"Beethoven pode ter ficado surdo para não escutar sua própria música", disse para ele em um momento em que nossos encontros já haviam chegado a um ano e também poderíamos pensar com ele em termos musicais. "Porque, por mais que ele tocasse música, era a música que deveria tocar ele de algum jeito. Noto que as coisas aqui não te tocam".
Nessa vinheta, pretendemos destacar o desvio da percepção do objeto estético em si para uma cegueira de si, em que também o objeto estético não pode se aproximar da consciência de Jaco. Ele costumava denominar as coisas para alcançar a racionalidade delas sobre si, mas o fazia porque não tinha condições de integrar essas experiências em forma de afeto. O uso da razão, por um lado, obstaculiza o sentir fluído dos sentidos. Logo, o imprevisível não pode acontecer como possibilidade a mais de ser visto e a dificuldade de investir em si mesmo para adquirir um prazer genuíno. Jaco espera que os outros digam o que ele precisa fazer. E isso também acontecia em nossos encontros.

Essa repetição foi aos poucos se tornando o ensaio de uma lenta música que um dia Jaco me trouxe, gravada por ele e tocada com um colega na viola de dez cordas. Uma música que trouxe a sensação desse lugar distante de onde vieram seus pais; podemos imaginar algo como uma serra no interior de Minas Gerais; uma cerca de madeira muito velha e sua porteira entreaberta, deixando histórias passarem por ela. Lembro-me de ter conversado com ele sobre o modo como sua melodia se aproximava dos contos de Guimarães Rosa (2001), em especial a história de "Famigerado", que veio a minha memória. Nesse conto, o narrador fala em primeira pessoa ${ }^{4}$ sobre como sua vida foi afetada quando um homem do governo informa a um jagunço perigoso, Damásio, que ele é famigerado. É exatamente ali, no portão de madeira, que a discussão acontece, pois Damásio desce da serra em que vive para pedir explicação sobre este termo para um homem letrado. O homem em questão diz: "Famigerado é inóxio, é 'célebre', 'notório', 'notável'..." (Rosa, 2001, p. 60). Contudo esse linguajar é muito complicado para seu entendimento, fato que o faz pedir novamente ao homem que explique mais facilmente: "Famigerado? Bem. É: 'importante', que merece louvor, respeito..." (Rosa, 2001, p. 60). Logo vemos Damásio saindo sossegado pela compreensão de que o termo famigerado era algo bom, uma vantagem, como o narrador deixa claro. Entretanto - e é neste fato que talvez fosse necessário adentrar -, ao final do conto, o cavalo de Damásio não pensava nisso. $\mathrm{O}$ animal não pensa, pois tem outro condicionamento, tal como a palavra famigerado também tem a conotação pejorativa de bandido. Uma palavra ambígua que, se fosse trazida na sua ampla concepção, além de atrapalhar seu sentido, poderia causar problemas ao narrador, temeroso de que poderia ser morto pelo jagunço.

Percebi o quanto essa questão da palavra também era um problema para Jaco ao entrar em detalhes e considerações racionais que por vezes, em vez de acalmá-lo, atormentavam-no, impedindo-o de entrar em contato com suas emoções. Aquilo que diz respeito ao que se é

4 Termo também compreendido pela teoria literária como narrador autodiegético. 
incapaz de nomear, tendo de optar antes pela vida e pela preservação, é aquilo com o que tivemos de estabelecer contato em nossas sessões. A cegueira precisa ser trazida para perto, pois talvez diga muito da música de Jaco, ainda que bela: Jaco vivia na aridez do seu sertão psíquico e, quando se aproximava das coisas, era rapidamente afastado por elas, sentindo-se mais inferior e incapaz de dar conta de sua vida adulta. Isso aconteceu quando o mesmo amigo lhe pedira mais temas para gravarem juntos e ele teve de dizer não ter mais. "Talvez isso mostre que, quando as pessoas tentam ajuda-lo, você consegue um jeito de afastá-las. Acho que isso acontece aqui comigo, eu também lhe peço mais repertórios, mais da sua percepção e criatividade, mas você não traz".

Nossa intenção, nessa ilustração clínica, é apontar para a dimensão estética de uma clínica psicanalítica. Estabelecemos assim uma dinâmica entre o estado mental de Jaco e o fluxo estético envolvendo memória, atenção, consciência e, inclusive, sua alucinação, esta última não como parte de uma falha de origens patológicas, mas como uma sensibilidade a ser aprendida e uma trajetória muito particular. Há uma dimensão afetiva submersa na tensão, que seria atravessar a barreira solidamente construída para não se deixar tocar - desvalimento que fica claro diante da surdez de sua audição. Tão claro que é preferível não se aproximar para não ter de prejudicar mais coisas em sua vida já danificada. Como investir em si mesmo sem parecer egoísta e arrogante? $\mathrm{E}$, do alto do muro de coisas criadas para não se deixar tocar, ele justamente prefere não tomar partido, preferindo o duro equilíbrio nas pontas sem envolvimento. Como lançar-se ao novo sem culpa? Também aqui a disponibilidade a não saber, mas se deixar envolver pela sensação do desconhecido.

\section{Considerações finais}

Neste artigo ensaiamos que o lugar do estético na repetição do artista corresponde à ação afetiva no outro, pois só assim alcança o efeito estético em si e se expande com sua obra. É parte do estético não nomeado, mas, antes, ensaia um estranhamento necessário para si mesmo. Estranhamento que também tentamos ver como um esgotamento das fórmulas utilizadas, como foi o caso de Jaco e do olhar que termina por causar uma cegueira, ponto de impotência sobre si.

Tal efeito estético, válido como forma de conhecimento da realidade, não é palpável conceitualmente, mas opera em uma zona intermediária, ou uma "terra de ninguém" (Pimenta, 2003), sugerindo uma associação com a própria teoria freudiana a respeito do terreno do estranho. Lê-se como terra de ninguém um espaço "de onde só pode ser recuperado por um observador que o realize também esteticamente; não de modo simbólico, mas dentro do espaço do seu horizonte estético" (Pimenta, 2003, p. 157). Esse caráter configura a irrepetibilidade da arte por meio das emoções.

Se analisarmos bem, essas considerações não parecem tão distantes dos questionamentos freudianos, embora evidentemente inseridos noutro discurso, outra leitura do discurso freudiano, tal como empreendida atualmente por autores como Roudinesco \& Derrida (2001). Por exemplo, Freud (1907a/2006) levanta indagações relacionadas à forma e ao gênero da obra escrita, que parecem sondar a seguinte questão: como e por qual motivo algumas formas escritas causam a sensação prazerosa e outras não? Não queremos com isso restringir o estético apenas ao prazer da leitura, mas colocá-lo entre mais um de muitos prazeres, talvez, o prazer mesmo que está na base da psicanálise e que diz respeito à formação de imagens inconscientes, tal como ocorre em "A interpretação dos sonhos" (Freud, 1900/2006). Aqui temos em mira imagens não acústicas, impressões antes de representações psíquicas, os lugares onde as coisas não estão determinadas por discursos. Talvez nossa época atual prefira os discursos, tanto os que aproximam quanto os que afastam as pessoas, para que o gigante buraco inexplorado da experiência estética continue silenciado pelas instituições que deveriam melhorar o espaço de recepção de nossa produção.

Contudo não podemos afirmar que, diante das indagações sobre o prazer, as respostas vão além da hipótese de que o fato se deve à mera manifestação do desejo inconsciente de seu autor. Caso contrário, para que repetir tanto? Parece haver uma repetição que ela também entra no círculo das coisas arruinadas, da barbárie da experiência humana após o fracionamento do eu que a psicanálise faz questão de salientar. E não é menor a nossa preocupação, uma vez que a cultura também é parte responsável e cega da composição coletiva das pessoas. "Nunca houve um documento de cultura que não fosse simultaneamente um documento de barbárie" (Benjamin, 2012, p. 245). Esse esfacelamento da cultura na qual a psicanálise também se mostra responsável, para além das escolas e dos sistemas que a obrigam a uma retirada (désaisissement) do objeto que se supõe conhecer como um todo. O próprio ideal de ciência que precisa ser repetida para possuir o caráter de fórmula e transmitir a ideia de perfeição metodológica ${ }^{5}$ e pureza abstrata. Talvez aqui a repetição mostre como cada tentativa é mais uma entre tantas de estabelecer uma aproximação com o desconhecido que nos envolve, impreterivelmente, cujo conflito teremos de enfrentar. 


\section{The unrepeatability of art}

Abstract: This article analyzes elements that function as repetitions in pieces of art. We demonstrate how repetition, together with Freud's concept of the uncanny (Unheimlich) can be seen in the artist's need to have a new encounter with the same piece in order to once again meet what is most radical in oneself. We utilize the contemporary aesthetic theory of Jacques Derrida and Georges Didi-Huberman as theoretical framework, as they observe the phenomenon of devaluation (désaisissement), which is an impossibility of visibility that causes a blindness towards the object. We present a brief clinical review of a case we dealt with wherein the experience of emotions is hampered, favoring the appearance of a repeated speech in the clinic.

Keywords: repetition, weird, aesthetics, devaluation.

\section{L'inimitabilité de l'art}

Résumé: L'article traite des éléments liés à la répétition comme une caractéristique de l'intentionnalité esthétique dans les œuvres d'art. Nous montrons comment la répétition, accompagnée de la réflexion freudienne sur l'étrange (Unheimlich), se manifeste dans le besoin de l'artiste de répéter une nouvelle rencontre avec l'œuvre, afin de produire une nouvelle rencontre avec le plus radical de lui-même. Nous illustrons cette idée avec les contributions apportées par la théorie esthétique contemporaine de Jacques Derrida et Georges Didi-Huberman, qui observent le phénomène de dessaisissement, une certaine impossibilité de visibilité qui provoque une cécité de l'objet. Nous présentons une brève revue clinique d'un cas que nous avons traité dans lequel l'expérience des émotions est entravée, favorisant l'apparition d'un discours répété dans la dimension de la clinique.

Mots-clés: répétition, étrange, l'esthétique, dessaisissement.

\section{La irrepetibilidad del arte}

Resumen: El artículo aborda los elementos vinculados a la repetición como característica de la intencionalidad estética en las obras de arte. Se plantea cómo la repetición, acompañada de la reflexión freudiana acerca del extraño (Unheimlich), se evidencia en la necesidad del artista de repetir un nuevo encuentro con la obra, con la intención de producir un nuevo encuentro con el más radical de sí. Para ello, se utilizó los aportes de la teoría estética contemporánea de Jacques Derrida y Georges DidiHuberman, quienes observan el fenómeno de desapoderamiento (désaisissement), una restricción de la visibilidad que produce una ceguera del objeto. Se presenta una breve reseña clínica sobre un caso atendido en que la vivencia de emociones es obstaculizada, favoreciendo la aparición de un habla repetida en la dimensión de la clínica.

Palabras clave: repetición, extraño, estética, desapoderamiento.

\section{Referências}

Benjamin, W. (2012). Sobre o conceito de história. In W. Benjamin, Magia e técnica, arte e política (S. P. Rouanet, trad., pp. 241-252). São Paulo, SP: Brasiliense.

Breton, A. (2001). Segundo manifesto do surrealismo. In A. Breton, Manifestos do surrealismo (S. Pachá, trad., pp. 13-64). Rio de Janeiro, RJ: Nau Editora.

Chklóvski, V. (2011). A arte como procedimento. In T. Todorov, Teoria da literatura: textos dos formalistas russos (R. L. Ferreira, trad., pp. 83-10). São Paulo, SP: Editora Unesp.

Derrida, J. (1967). L'écriture et la différence. Paris: Éditions du Seuil.

Derrida, J. (2010). Memórias de cego: o auto-retrato e outras ruinas (F. Bernardo, trad.). Lisboa: Fundação Calouste Gulbenkian.

Derrida, J. (2011). El tocar, Jean-Luc Nancy (I. Agoff, trad.). Buenos Aires: Amorrortu.
Didi-Huberman, G. (2010). O que vemos, o que nos olha (P. Neves, trad.). São Paulo, SP: Editora 34.

Freud, S. (2006). A interpretação dos sonhos. In Edição standard brasileira das obras psicológicas completas de Sigmund Freud (J. Salomão, trad., Vol. 5, pp. 39-169). Rio de Janeiro, RJ: Imago. (Trabalho original publicado em 1900)

Freud, S. (2006). Os chistes e sua relação com o inconsciente. In Edição standard brasileira das obras psicológicas completas de Sigmund Freud (J. Salomão, trad., Vol. 8, pp. 17-171). Rio de Janeiro, RJ: Imago. (Trabalho original publicado em 1905)

Freud, S. (2006). Escritores criativos e devaneios. In Edição standard brasileira das obras psicológicas completas de Sigmund Freud (J. Salomão, trad., Vol. 9, pp. 133-147). Rio de Janeiro, RJ: Imago. (Trabalho original publicado em 1907a) 
Freud, S. (2006). Delírios e sonhos na Gradiva de Jensen. In Edição standard brasileira das obras psicológicas completas de Sigmund Freud (J. Salomão, trad., Vol. 9, pp. 15-87). Rio de Janeiro, RJ: Imago. (Trabalho original publicado em 1907b)

Freud, S. (2006). Formulações sobre os dois princípios do funcionamento mental. In Edição standard brasileira das obras psicológicas completas de Sigmund Freud (J. Salomão, trad., Vol. 12, pp. 233-247). Rio de Janeiro, RJ: Imago. (Trabalho original publicado em 1911)

Freud, S. (2006). O Moisés de Michelangelo. In Edição standard brasileira das obras psicológicas completas de Sigmund Freud (J. Salomão, trad., Vol. 13, p. 213-243). Rio de Janeiro, RJ: Imago. (Trabalho original publicado em 1914)

Freud, S. (2006). O estranho. In Edição standard brasileira das obras psicológicas completas de Sigmund Freud (J. Salomão, trad., Vol. 17, p. 235-277). Rio de Janeiro, RJ: Imago. (Trabalho original publicado em 1919)

Freud, S. (2010). O inquietante. In Obras Completas: História de uma Neurose Infantil (O homem dos lobos), Além do princípio do prazer e outros textos (P. C. Souza, trad., Vol. 14, pp. 328-377). São Paulo, SP: Companhia das Letras. (Trabalho original publicado em 1919)

Freud, S. (2019). O infamiliar e outros escritos. In Obras incompletas de Sigmund Freud (E. Chaves \& P. H. Tavares, trad., pp. 27-127). Belo Horizonte, MG: Autêntica. (Trabalho original publicado em 1919)

Gagnebin, M. (2015). Glossaire des principales notions élaborées par 1'auteur. In M. M'uzan, L'Inquiétude Permanente. Paris: Gallimard.

Hanns, L. A. (1996). Dicionário comentado do alemão de Freud. Rio de Janeiro, RJ: Imago.

Laplanche, J., \& Pontalis, J.-B. (1970). Vocabulário de psicanálise (P. Tamen, trad.). São Paulo, SP: Martins Fontes. (Trabalho original publicado em 1967)
Lehalle, B. (2012). Synthèse méthodologique de l'approche psychanalytique des arts plastiques. In H. Bessis \& A. Clancier, Psychanalyse des arts de l'image (pp. 11-21). Paris: Hermann Éditeurs.

Loureiro, I. (2003). Sobre as várias noções de estética em Freud. Pulsional: Revista de Psicanálise, 16(175), 23-32.

M'Uzan, M. (2010). Créativité et addictions. In Cupa, D. et al. Entre corps et psyché: les addictions. Paris: EDK.

M'Uzan, M. (2012). Le saisissement créateur. In M. Gagnebin \& J. Milly (Orgs.), Michel de M'Uzan ou le saisissement créateur. Autor de l'ouvre théorique et fictionelle (pp. xx-xx). Seyssel: Éditons Champ Vallon.

M'Uzan, M. (2015). L'inquietude permanente. Paris: Gallimard.

Pimenta, A. (2003). O silêncio dos poetas, precedido de Reflexões sobre a função da arte literária e de A dimensão poética das línguas. Lisboa: Cotovia.

Rech, M., \& Ketzer, E. N. (2017). Estranhamento e sensorialidade na experiência da psicanálise. Polêm!ca, 17(2), 68-83.

Rosa, G. (2001). Primeiras estórias. Rio de Janeiro, RJ: Nova Fronteira, 2001.

Roudinesco, E., \& Derrida, J. (2001). De quoi demain... Dialogue. Paris: Flammarion.

Schneider, M. (2008). Freud et le combat avec l'artiste. InJ.Mcdougaletal.L'artisteetlePsychanaliste(pp.47-71). Paris: Presses Universitaires de France.

Terrapon, M. (2012). L'inspiration en tant qu'incarnation au monde. In H. Bessis \& A. Clancier, Psychanalyse des arts de l'image. Paris: Hermann Éditeurs.

Submissão: 25/07/2018

Revisão: $29 / 08 / 2019$

Aprovação: 26/07/2020 